\title{
Outcomes of patients with COVID-19 acute respiratory distress syndrome requiring invasive mechanical ventilation admitted to an intensive care unit in South Africa
}

\author{
C Arnold-Day, ${ }^{1} \mathrm{MB}$ BCh, MMed (Neurosurg) (D; R N van Zyl-Smit, ${ }^{2} \mathrm{MB}$ ChB, PhD; I A Joubert, ${ }^{1}$ MB BCh; D A Thomson, ${ }^{1,3}$ MB ChB, \\ MMed (Surg); D L Fredericks, ${ }^{1}$ MB ChB; M G A Miller, ${ }^{1}$ MB ChB; W L Michell, ${ }^{1,3}$ MB ChB; P L Semple, ${ }^{4}$ MB ChB, PhD; J L Piercy, ${ }^{1}$ MBBS \\ ${ }^{1}$ Division of Critical Care, Department of Anaesthesia and Perioperative Medicine, University of Cape Town and Groote Schuur Hospital, \\ Cape Town, South Africa \\ ${ }^{2}$ Division of Pulmonology, Department of Medicine, University of Cape Town and Groote Schuur Hospital, Cape Town, South Africa \\ ${ }^{3}$ Department of Surgery, University of Cape Town and Groote Schuur Hospital, Cape Town, South Africa \\ ${ }^{4}$ Department of Neurosurgery, University of Cape Town and Groote Schuur Hospital, Cape Town, South Africa.
}

Corresponding author: J L Piercy (jenna.piercy@uct.ac.za)

\begin{abstract}
Background. Up to $32 \%$ of patients with COVID-19 pneumonia may require intensive care unit (ICU) admission or mechanical ventilation. Data from low- and middle-income countries on COVID-19 acute respiratory distress syndrome (ARDS) are limited. Groote Schuur Hospital in Cape Town, South Africa, expanded its intensive care service to support patients with COVID-19 ARDS requiring invasive mechanical ventilation (IMV).

Objectives. To report on patients' characteristics and outcomes from the first two pandemic waves.

Methods. All patients with COVID-19 ARDS admitted to the ICU for IMV were included in this prospective cohort study. Data were collected from 5 April 2020 to 5 April 2021.

Results. Over the 12-month study period, 461 patients were admitted to the designated COVID-19 ICU. Of these, 380 met the study criteria and 377 had confirmed hospital discharge outcomes. The median (range) age of patients was 51 (17 - 71) years, 50.5\% were female, and the median (interquartile range (IQR)) body mass index was $32(28-38) \mathrm{kg} / \mathrm{m}^{2}$. The median (IQR) arterial oxygen partial pressure to fractional inspired oxygen (P/F) ratio was 97 (71 - 128) after IMV was initiated. Comorbidities included diabetes (47.6\%), hypertension (46.3\%) and HIV infection (10.5\%). Of the patients admitted, 30.8\% survived to hospital discharge with a median (IQR) ICU length of stay of 19.5 (936) days. Predictors of mortality after adjusting for confounders were male sex (odds ratio (OR) 1.74), increasing age (OR 1.04) and higher Sequential Organ Failure Assessment (SOFA) score (OR 1.29).

Conclusions. In a resource-limited environment, the provision of IMV support in the ICU achieved $30.8 \%$ hospital survival in patients with COVID-19 ARDS. The ability to predict survival remains difficult given this complex disease.

S Afr Med J 2022;112(1):34-39. https://doi.org/10.7196/SAMJ.2022.v112i1.16115
\end{abstract}

It is estimated that $5-32 \%$ of patients hospitalised with severe COVID-19 require intensive care unit (ICU) admission or mechanical ventilation. ${ }^{[1,2]}$ Identification of prognostic factors in critically ill patients with COVID-19 is vital to guide decision-making, especially in resource-constrained environments with limited ability to expand critical care capacity. Ethical allocation of resources with early effective triaging of patients is dependent on local data to ensure equitable and appropriate admission to critical care services.

Information on the clinical characteristics and outcomes of COVID19 patients requiring ICU admission in low- and middle-income countries (LMICs) is limited. ${ }^{[3]}$ Several countries in Asia, Europe and North and South America have published mortality outcomes ranging from $16.2 \%$ to $94 \%{ }^{[4-6]}$ for patients with COVID-19 acute respiratory distress syndrome (ARDS) admitted to the ICU for invasive mechanical ventilation (IMV). In South Africa (SA), a middle-income country, >1.55 million cases of COVID-19 had been confirmed over two pandemic waves, with nearly 53000 deaths, as of 5 April 2021. ${ }^{[7]}$

\section{Objectives}

To describe the clinical characteristics, course and outcomes of critically ill patients with COVID-19 ARDS admitted to the ICU for IMV at Groote Schuur Hospital (GSH), Cape Town, SA, during the first two waves of the COVID-19 pandemic. GSH is a 991-bed, public sector tertiary-level teaching hospital affiliated to the University of Cape Town.

\section{Methods}

Study design, population and time frame

This was a prospective, single-centre cohort study of all patients with laboratory-confirmed SARS-CoV-2 pneumonia and ARDS who were intubated and received IMV. Patients admitted to the ICU between 5 April 2020 and 5 April 2021 were entered into the study. This period covers the first and second waves of the COVID-19 pandemic in SA.

As per the hospital response plan, admission to the COVID-19 ICU was only for intubated patients requiring IMV. Standard hospital wards were repurposed to provide supplemental oxygen, including high-flow nasal oxygen (HFNO), outside of the ICU.

COVID-19 ICU bed capacity was dynamic and expanded to accommodate extra patients as needed. At maximum capacity, 43 COVID-19 ICU beds were managed by 3 intensivist-led ICU teams, with 2 registered nurses and 2 nursing assistants allocated to each 6-bed patient cluster. A regional ICU triage tool was in effect prior to the first wave (Appendix 1, available online at http://samj.org.za/ public/sup/16115.pdf). 
COVID-19 ARDS was defined as a positive SARS-CoV-2 reversetranscriptase polymerase chain reaction assay of a nasopharyngeal swab or tracheal aspirate as per World Health Organization guidelines $^{[8]}$ in a patient with primary ARDS meeting the Berlin criteria $^{[9]}$ with an arterial oxygen partial pressure to fractional inspired oxygen $(\mathrm{P} / \mathrm{F})$ ratio of $<300$ measured on day 1 of ICU admission.

Ethics approval for this study was granted by the University of Cape Town Human Research Ethics Committee (ref. no. 362/2020). Consent was obtained for survivors and waived for patients who died.

\section{Data collection}

Patient clinical and outcome data were collected prospectively from 5 April 2020 to 5 April 2021. Data were collected on the daily ward round and from the electronic laboratory and radiological systems.

Data were captured for all patients admitted, and no imputation was conducted for missing variables. Data were entered on an anonymised and password-protected database. Comparisons between groups were performed using appropriate parametric and non-parametric analyses, and stepwise multivariate logistic regression modelling was performed to identify predictors of mortality. Data analysis was conducted using GraphPad Prism for Mac V9.02 (Apple, USA; www.graphpad.com). Data are presented using descriptive statistics.

\section{Results}

A total of 461 patients were admitted to the COVID-19 ICU service for IMV, of whom 32 did not meet the criteria for laboratoryconfirmed SARS-CoV-2 infection, 23 did not meet the criteria for ARDS, and 26 were admitted with an alternative primary diagnosis and found to have coincidental SARS-CoV-2 infection. These patients were excluded from the study. Data from all 380 patients with confirmed COVID-19 ARDS were included in the final analysis (Fig. 1).

The demographics, clinical characteristics and outcomes of all COVID-19 ARDS patients are shown in Table 1. The median (interquartile range (IQR)) patient age was $51(43-58)$ years, with a range of $17-71$ years. Comorbidities were common, with nearly $80 \%$ of patients having at least one comorbid condition, the most frequent being diabetes mellitus (47.6\%) and hypertension (46.3\%). Obesity was common (62.6\%), with a median (IQR) body mass index (BMI) of $32(28-38) \mathrm{kg} / \mathrm{m}^{2}$. Over $75 \%$ of female patients were obese, with a median BMI of $35 \mathrm{~kg} / \mathrm{m}^{2}$ compared with $29 \mathrm{~kg} /$ $\mathrm{m}^{2}$ for males $(p<0.001)$ (not shown in the table). Forty patients (10.5\%) had HIV co-infection, with generally preserved CD4 counts (median (IQR) $258(166.8$ - 440) cells/ $\mu \mathrm{L}$ ). Male and female patients were similar in baseline characteristics, except for BMI.

Of the 380 patients, 3 were still in the ICU at the time of data analysis; of the 377 patients with known hospital outcomes, there

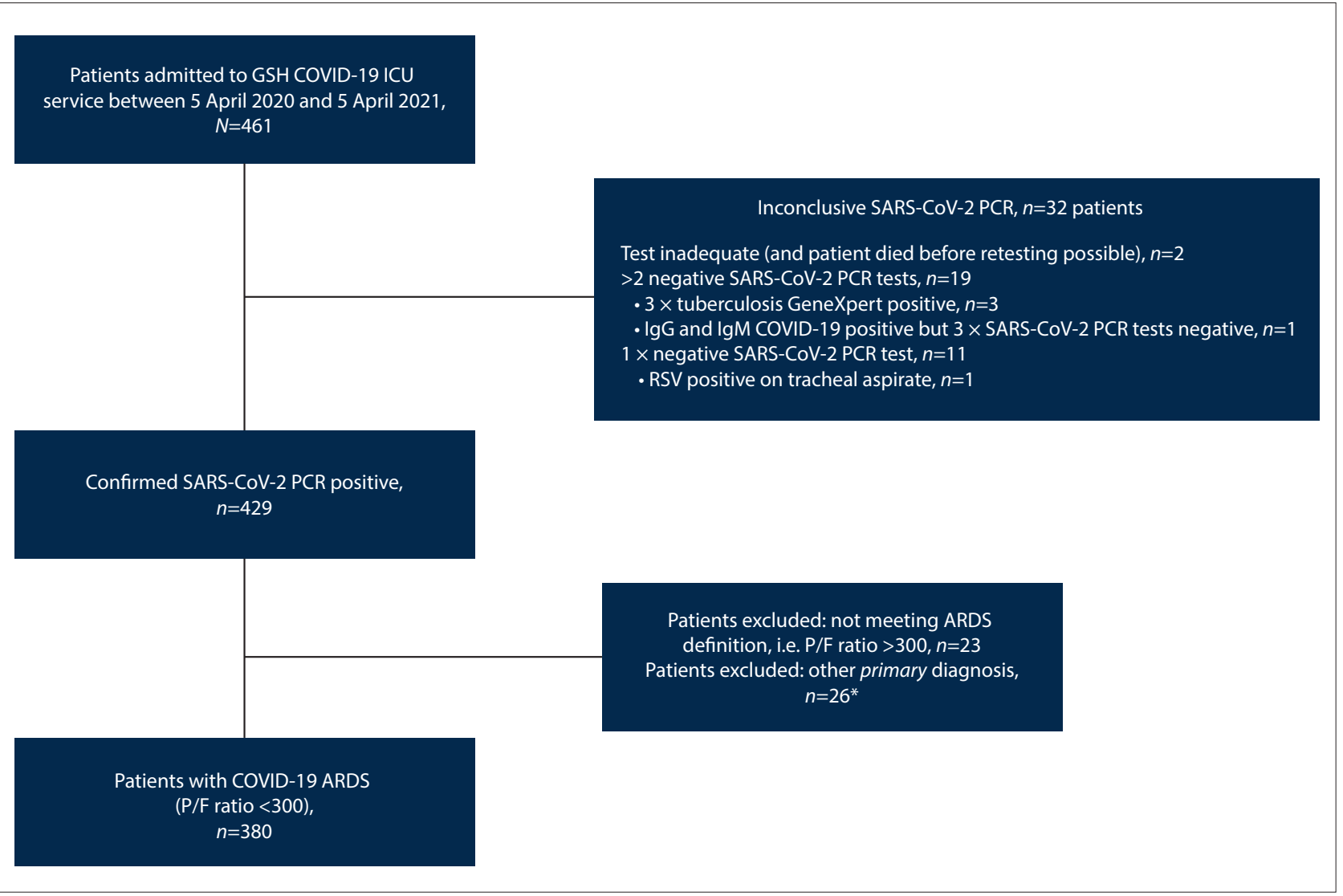

Fig. 1. Consort diagram of patient inclusion and analysis. $(I C U=$ intensive care unit; $P C R=$ polymerase chain reaction; $R S V=$ respiratory syncytial virus; $A R D S=$ acute respiratory distress syndrome; $P / F$ ratio $=$ arterial oxygen partial pressure to fractional inspired oxygen ratio; $* 26$ diagnoses: $3 \times$ patients with multiple thoracoabdominal gunshot wounds; $2 \times$ ethyl glycol poisoning with acute kidney injury; necrotising fasciitis of groin; bowel obstruction and septic shock; pituitary macroadenoma with acute hydrocephalus; gunshot head injury; thoracoabdominal polytrauma after motor vehicle accident; perforated diverticulitis with septic shock; penetrating head injury; lupus nephritis with septic shock, acute kidney injury and pulmonary oedema; mucormycosis; subarachnoid haemorrhage from mycotic aneurysm secondary to infective endocarditis; diabetic ketoacidosis in septic shock; stabbed heart injury; rheumatic heart disease admitted for valve replacement; $2 \times$ acute severe pancreatitis; severe polytrauma after pedestrian-vehicle accident; gunshot wound to the chest; lymphoma in septic shock with acute kidney injury; penetrating neck injury; $2 \times$ acute psychosis.) 
Table 1. Clinical and laboratory characteristics of patients admitted with severe COVID-19 ARDS to the ICU at Groote Schuur Hospital, Cape Town

\begin{tabular}{|c|c|c|c|c|}
\hline & All patients & Survivors & Non-survivors & $p$-value \\
\hline Patients, $n(\%)$ & $377(100)$ & $116(30.8)$ & $261(69.2)$ & \\
\hline Age (years), median (IQR) & $51(43-58)$ & $48(40-55)$ & $53(45.5-59)$ & $<0.001^{\star}$ \\
\hline \multicolumn{5}{|l|}{ Sex, $n(\%)$} \\
\hline Male & $185(49.5)$ & $44(37.9)$ & $141(54.0)$ & \\
\hline Female & $192(50.5)$ & $72(62.1)$ & $120(46.0)$ & 0.005 \\
\hline Peripartum & $25(13.0)$ & $12(16.7)$ & $13(10.8)$ & \\
\hline Non-peripartum & $167(87.0)$ & $60(83.3)$ & $107(89.2)$ & $0.002^{*}$ \\
\hline \multicolumn{5}{|l|}{ Comorbidities } \\
\hline None, $n(\%)$ & $69(18.3)$ & $22(19.0)$ & $47(18.0)$ & 0.885 \\
\hline Hypertension, $n(\%)$ & $176(46.3)$ & $51(44.0)$ & $125(47.9)$ & 0.504 \\
\hline DM, $n(\%)$ & $181(47.6)$ & $47(40.5)$ & $134(51.3)$ & 0.580 \\
\hline HbAlc (\%) in known DM, median (IQR) & $9.5(7.1-11.8)$ & $9.8(6.8-12.4)$ & $9.4(7.3-11.7)$ & 0.599 \\
\hline HIV infected, $n(\%)$ & $40(10.5)$ & $9(7.8)$ & $31(11.8)$ & 0.280 \\
\hline CD4 count (cells/ $\mu \mathrm{L}),($ median, IQR) & $258(166.8-440)$ & $278(125-562)$ & $249(164-452)$ & 0.886 \\
\hline BMI $\left(\mathrm{kg} / \mathrm{m}^{2}\right)$, median $(\mathrm{IQR})$ & $32(28-38)$ & $33(28-38.8)$ & $31(27.5-38)$ & 0.296 \\
\hline Symptom onset to ICU admission (days), median (IQR) & $9(7-14)$ & $8(6-11)$ & $10(7-15)$ & $0.002^{*}$ \\
\hline ICU length of stay (days), median (IQR) & $10(5-20)$ & $19.5(9-36)$ & $7(3-14)$ & $<0.001^{\star}$ \\
\hline Respiratory therapy prior to ICU admission, $n(\%)$ & & & & 0.412 \\
\hline HFNO & $299(79.3)$ & $89(76.7)$ & $210(80.5)$ & \\
\hline Non-HFNO & $78(20.5)$ & $27(23.3)$ & $51(19.5)$ & \\
\hline Day 1 SOFA score, median (IQR) & $4(4-7)$ & $4(3-5)$ & $5(4-8)$ & $<0.001^{\star}$ \\
\hline Day 1 P/F ratio, median (IQR) & $97(71-128)$ & $109(81-145)$ & $90(69-121)$ & $<0.001^{\star}$ \\
\hline \multicolumn{5}{|l|}{ Admission laboratory results ${ }^{\dagger}$ (median, IQR) } \\
\hline Creatinine $(\mu \mathrm{mol} / \mathrm{L})$ & $85.5(66-109)$ & $79.5(60.3-109)$ & $87(68.5-109)$ & $0.091^{*}$ \\
\hline WCC $\left(\times 10^{9} / \mathrm{L}\right)$ & $9.4(7.0-14.4)$ & $10.3(7.5-15.7)$ & $9.5(7.3-14)$ & $0.133^{*}$ \\
\hline Lymphocyte count $\left(\times 10^{9} / \mathrm{L}\right)$ & $1.2(0.9-1.8)$ & $1.37(1-2)$ & $1.2(0.9-1.6)$ & $0.092^{*}$ \\
\hline Platelet count $\left(\times 10^{9} / \mathrm{L}\right)$ & $248(188-322)$ & $251(195-326)$ & $244(188-321)$ & $0.490^{*}$ \\
\hline $\mathrm{CRP}(\mathrm{mg} / \mathrm{L})$ & $145(76-260)$ & $175(98-258)$ & $161(86-279)$ & $0.765^{*}$ \\
\hline D-dimers $(\mathrm{mg} / \mathrm{L})$ & $0.67(0.40-2.23)$ & $0.7(0.47-1.65)$ & $0.76(0.42-2.43)$ & $0.994^{*}$ \\
\hline HbAlc (\%) & $6.8(6.2-9.7)$ & $6.5(6-9.3)$ & $6.9(6.3-10.1)$ & $0.009^{*}$ \\
\hline \multicolumn{5}{|l|}{ Additional ICU therapy, $n$ (\%) } \\
\hline Vasopressor support & $244(64.2)$ & $44(37.9)$ & $197(75.5)$ & $<0.001^{\star}$ \\
\hline Renal replacement therapy & $57(15.0)$ & $10(8.6)$ & $45(17.2)$ & $<0.001^{\star}$ \\
\hline VV-ECMO & $6(1.6)$ & $3(2.6)$ & $3(1.2)$ & $0.377^{*}$ \\
\hline Tracheostomy & $78(20.5)$ & $53(45.7)$ & $25(9.6)$ & $<0.001^{\star}$ \\
\hline \multicolumn{5}{|c|}{ 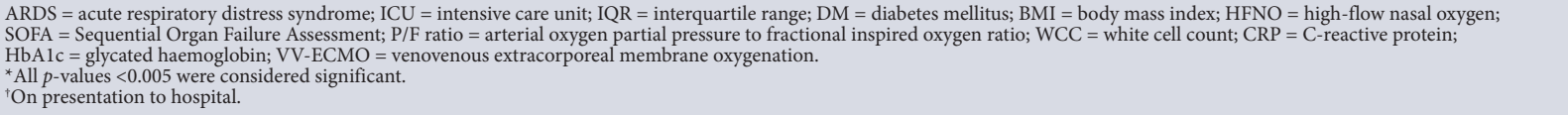 } \\
\hline
\end{tabular}

were 116 survivors (30.8\%). Survivors had a median (IQR) age of $48(40-55)$ years v. $53(45.5$ - 59) years for non-survivors $(p<0.001)$. The survival rate for males $(23.7 \% ; n=44 / 185)$, was lower than that for females $(37.5 \% ; n=72 / 192)(p=0.011)$. Twentyfive of the female patients were peripartum, with an appreciably better survival of $48.0 \%(n=12 / 25)$ compared with non-peripartum females $(35.9 \% ; n=60 / 167)(p=0.02)$. Male survival remained lower than that for females even when excluding the peripartum group $(p=0.041)$.

There were no statistically significant differences in comorbidities between survivors and non-survivors (Table 1).

The median duration of symptoms prior to ICU admission was 9 days, with a bimodal distribution with peaks at day 3 and day 7 and a long tail out to 41 days (Fig. 2). The duration of symptoms prior to the need for IMV was significantly shorter in survivors compared with non-survivors ( 8 days v. 10 days; $p<0.02$ ). A receiver operating characteristic curve analysis (area under the curve 0.6) cut-off of 20 days of symptom duration prior to the initiation of IMV was associated with a likelihood ratio for mortality of 2.3 (95.6\% specificity, sensitivity $9.9 \%$ ).

Overall ICU length of stay ranged from $<1$ day to 121 days. The median (IQR) length of ICU stay was 19.5 (9 - 36) days for survivors v. $7(3-13)$ days for non-survivors $(p<0.001)$ (Table 1). All ICU survivors $(n=121)$ were followed up until hospital discharge. Five patients died in hospital after ICU discharge.

A total of 299 patients (79.3\%) failed HFNO prior to requiring IMV and admission to the ICU. The median (IQR) P/F ratio was 97 (71 - 128) after IMV was initiated on day 1 in the ICU. The day 1 median (IQR) Sequential Organ Failure Assessment (SOFA) score was $4(4-7)$. Survivors were younger than non-survivors (median (IQR) $48(40$ - 55) years v. $53(45.5$ - 59) years $(p=0.001))$, and had lower SOFA scores and glycated haemoglobin $(\mathrm{HbAlc})$ levels, and 
higher day $1 \mathrm{P} / \mathrm{F}$ ratios. No differences in laboratory characteristics (including white cell count, D-dimers and C-reactive protein) were noted between survivors and non-survivors.

The requirement for renal replacement therapy (RRT) or vasopressors was associated with poor outcomes.

In a univariate analysis, increasing age, male gender, lower day 1 $\mathrm{P} / \mathrm{F}$ ratio, duration of symptoms prior to ICU admission and higher day 1 SOFA score were associated with mortality (Table 2). The presence of comorbidities (diabetes mellitus, hypertension, HIV infection), raised BMI and peripartum status were not predictors of mortality. After adjusting for confounders in a multivariate model, male gender (odds ratio (OR) 1.74), increasing age (OR 1.04) and higher day 1 SOFA score (OR 1.29) remained significant predictors of mortality.

\section{Discussion}

This is the first study to report on outcome data for COVID-19 ARDS patients admitted to the ICU requiring IMV from sub-Saharan Africa. We included all patients admitted to the ICU and had hospital outcomes for $>99 \%$ of patients.

Our outcomes are challenging to interpret in relation to published international experience. Studies early in the global pandemic reported mortality rates from $0 \%{ }^{[10]}$ (expressed as 30-day hospital mortality) to as high as $97 \%$ for patients receiving IMV $^{[11]}$ Most studies include a mixture of invasive and non-invasive mechanical respiratory support in the ICU, rather than IMV cohorts alone. In studies with outcome data for patients receiving IMV, mortality rates vary widely from $11.1 \%$ to $91.4 \%{ }^{[12-17]}$ In these studies, the mortality rates were not consistently reported for the whole cohort or subgroup

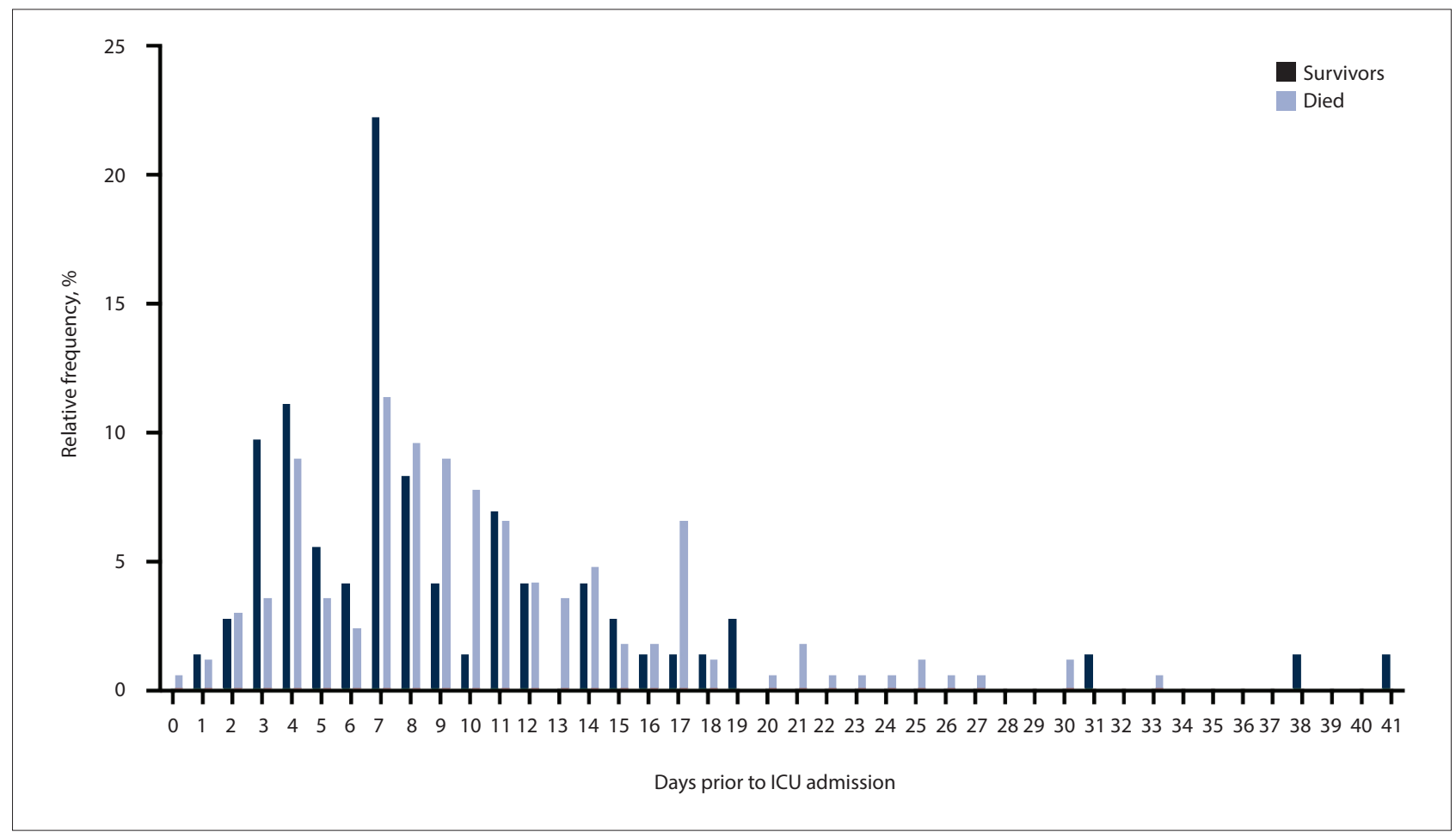

Fig. 2. Duration of symptoms prior to ICU admission by survival status. (ICU = intensive care unit.)

\begin{tabular}{|c|c|c|}
\hline Variable & OR & $95 \% \mathrm{CI}$ \\
\hline \multicolumn{3}{|l|}{ Univariate analysis } \\
\hline Age & 1.042 & $1.021-1.064$ \\
\hline Male & 1.923 & $1.234-3.022$ \\
\hline $\mathrm{HbAlc}$ & 1.060 & $0.972-1.161$ \\
\hline Days from symptom onset to ICU admission & 1.043 & $1.005-1.086$ \\
\hline Day 1 ICU SOFA score & 1.308 & $1.169-1.480$ \\
\hline Estimated BMI & 0.979 & $0.951-1.007$ \\
\hline HIV & 1.544 & $0.735-3.560$ \\
\hline Day $1 \mathrm{ICU} \mathrm{P} / \mathrm{F}$ ratio & 0.992 & $0.987-0.997$ \\
\hline \multicolumn{3}{|l|}{ Multivariate analysis } \\
\hline Age & 1.038 & $1.016-1.062$ \\
\hline Admission SOFA score & 1.287 & $1.153-1.453$ \\
\hline Male gender & 1.739 & $1.090-2.791$ \\
\hline
\end{tabular}


requiring IMV. Comparisons of outcomes are further complicated by lack of reporting on staffing ratios, bed capacity and resource availability, including RRT, tracheostomy and extracorporeal membrane oxygenation (ECMO).

To give context to our reported cohort, only patients who required IMV were admitted to the ICU. No patients received HFNO or any other form of non-invasive or oxygen therapy on admission to the ICU. A medical team provided HFNO, self-proning and corticosteroid therapy to patients with severe hypoxia but not requiring intubation, in repurposed medical wards. ${ }^{[18,19]}$ Patients who failed HFNO and fulfilled triage criteria were referred to the ICU. The fact that the majority of patients admitted to our ICU (79.5\%) had failed HFNO implies that IMV was frequently initiated as a salvage therapy. This may account for our median day $1 \mathrm{P} / \mathrm{F}$ ratio of only 97 . The late initiation of IMV for HFNO failures may have a negative impact on survival. At the time of data analysis, there were no prospective randomised controlled trials comparing HFNO with IMV for COVID-19 ARDS, but subsequent data from the RISC-19ICU study have shown that in patients with COVID-19, a trial of HFNO appeared to be the most balanced initial respiratory support strategy, with reduced intubation rates and comparable ICU mortality rates compared with standard oxygen therapy and early IMV. ${ }^{[20]}$ The stepwise escalation of oxygen therapy was driven by resource constraints in our setting.

A consensus triage guidance tool was drafted by the Critical Care Society of Southern Africa, ${ }^{[21]}$ and was modified by the regional Department of Health ${ }^{[22]}$ to assist in allocating the use of ICU resources during the COVID-19 pandemic. This triage tool, implemented by the ICUs at GSH and across the region, excluded patients with poor functional status or severe multiorgan failure prior to admission. The triage tool was based on the Ventilator Allocation Guidelines drafted by the New York State Task Force on Life and the Law, by the New York State Department of Health. ${ }^{[23]}$ The New York document, from a high-income country, was modified as there were no available triage guidelines from LMIC countries at the beginning of the COVID-19 pandemic.

At the height of the COVID-19 waves, pressure on resources resulted in a limited supply of ICU beds, necessitating tighter triaging and the admission of patients who were assessed as being the highest priority for ventilatory support only. Later in the pandemic, as the number of referrals waned, triaging was less strict and patients assessed as being intermediate priority for ventilatory support were considered for ICU admission, in accordance with the consensus triage tool and the availability of resources. Fig. 3A - D illustrates the graphical data for the first two waves, nationally as well as provincial data for Western Cape Province. These graphs also depict the start of the third wave being experienced in SA at the time of writing (data analysis does not include patients from the third wave).

The presence of comorbidities (81.7\%), although associated with the development of severe disease, did not predict mortality in this cohort receiving IMV. This finding suggests that the number of comorbidities was not discriminatory for outcome in this

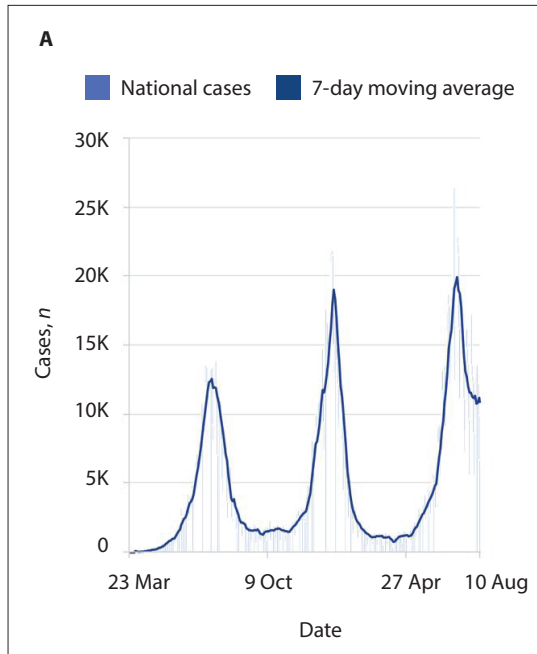

c
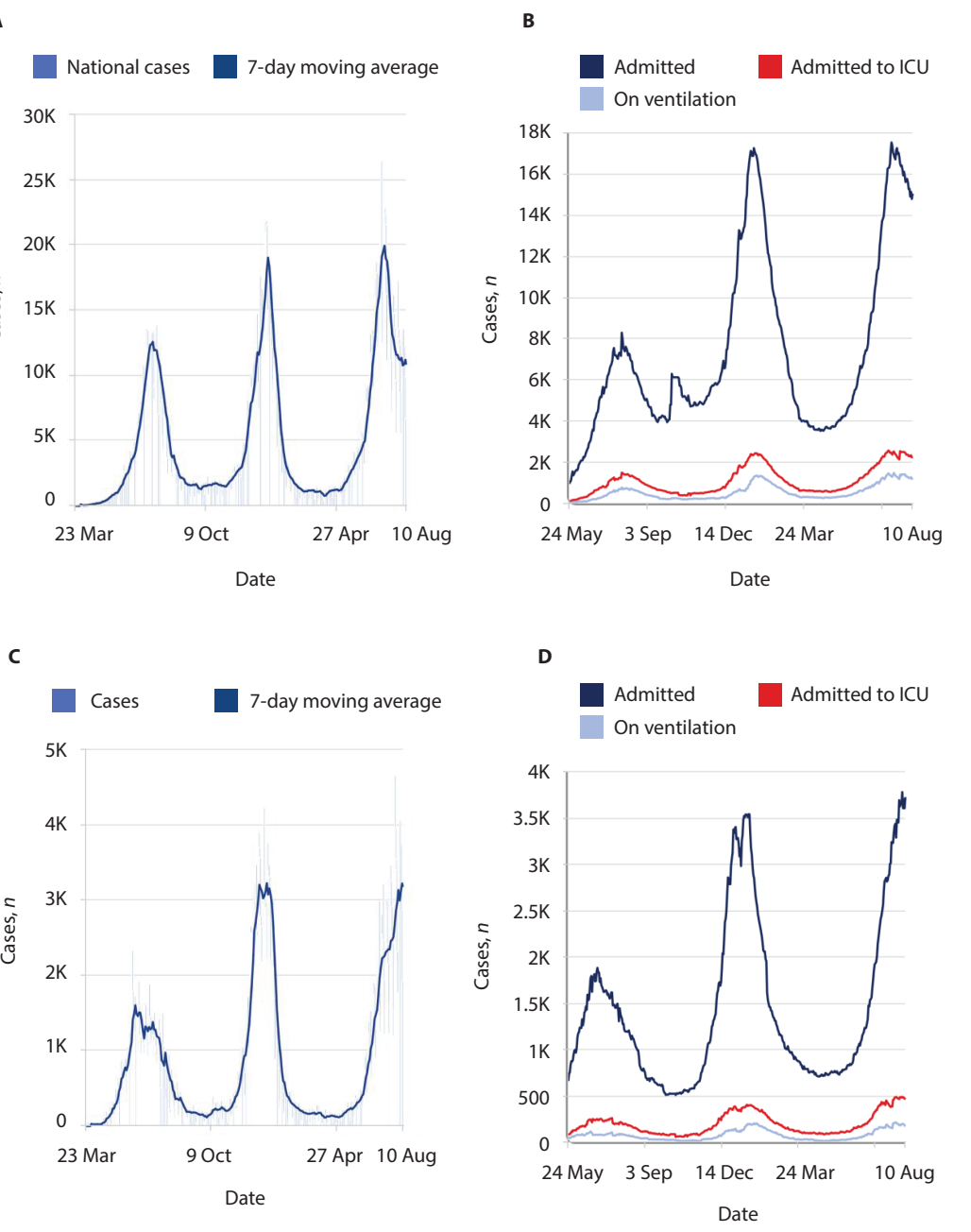

Fig. 3. Data for the first two waves of COVID-19 in South Africa, 2020/2021 (the start of the third wave is also depicted). (A) National daily new COVID-19 cases (7-day moving average); (B) national hospitalisations of COVID-19 cases; (C) daily new COVID-19 cases (7-day moving average) in Western Cape province; (D) hospitalisations of COVID-19 cases in Western Cape. Figures adapted with permission from News24's COVID-19 dashboard, ${ }^{[24]}$ data source National Department of Health and National Institute for Communicable Diseases. (ICU = intensive care unit.) 
the prolonged trajectory of recovery in patients requiring IMV for COVID-19 ARDS. In our setting, patients were only discharged from the ICU once liberated from IMV.

Our management strategies included lung protective ventilatory strategies, ${ }^{[9]}$ the use of neuromuscular blocking agents, sedation, and the liberal use of prolonged prone positioning (for periods of up to 16 hours). Anticoagulant therapy, using mainly low-molecular-weight heparin, was guided by anti-Xa levels. The use of dexamethasone was instituted shortly after the positive data from the RECOVERY trial were released. ${ }^{[25]}$ Prior to this, corticosteroid use was at the discretion of the treating physician. Despite international controversy, no patients received hydroxychloroquine, remdesivir, tocilizumab, ivermectin, convalescent plasma or other experimental therapy.

GSH is a designated regional ECMO referral centre. ECMO was available for patients with COVID-19 ARDS, but owing to high resource demands, particularly nursing, the use of ECMO was severely limited. Each patient receiving ECMO is cared for by a dedicated registered nurse, putting further pressure on nursing capacity.

On 18 December 2020, a new SARS-CoV-2 variant (501.V2) was identified as being the dominant strain in the second wave in SA. ${ }^{[26]}$ In our cohort, it is not possible to determine which variant of the SARS-CoV-2 virus infected patients, and whether this had an impact on outcomes. The Johnson \& Johnson's Janssen COVID-19 vaccine roll-out commenced in SA on 17 February 2021. As of 5 April 2021, less than $0.5 \%$ of the SA population had been vaccinated. Vaccination is unlikely to have had any impact on our cohort at all.

\section{Conclusions}

Patients with COVID-19 ARDS who required IMV admission to a tertiary ICU in Cape Town during the first and second wave of the pandemic in SA had an overall hospital survival of 30.8\%, and survivors had a median length of ICU stay of 19.5 days.

SARS-CoV-2-infected patients with severe acute hypoxaemic respiratory failure require prolonged IMV, leading to high resource utilisation. In an African LMIC setting with strict triage criteria, we were unable to identify clinically useful prognostic factors in patients admitted for IMV. Interpretation of critical care patient outcomes during a pandemic that overwhelms healthcare systems is challenging. Larger standardised data sets may help shed light on strategies to improve patient selection and outcome. Crucial would be uniformity in defining the context in which critical care was delivered, including IMV and the reporting of standardised ICU and hospital outcomes.

\section{Declaration. None.}

Acknowledgements. We extend our gratitude to all our ICU colleagues at GSH who worked so hard to provide excellent care to our patients during this global pandemic. We acknowledge all families affected by COVID-19 and the many who lost loved ones.

Author contributions. CA-D and JLP assisted with data collection. CA-D and RNvZ-S analysed data. All authors had access to the data set, assisted with data review and manuscript preparation, and approved the final manuscript.

Funding. None.

Conflicts of interest. None.

1. Huang C, Wang Y, Li X, et al. Clinical features of patients infected with 2019 novel coronavirus in Wuhan, China. Lancet 2020;395(10223):497-506. https://doi.org/10.1016/s0140-6736(20)30183-5

2. Guan W-J, Ni Z-Y, Hu Y, et al. Clinical characteristics of coronavirus disease 2019 in China. N Engl J Med 2020;382:1708-1720. https://doi.org/10.1056/nejmoa2002032

3. Biccard B, Miller MG, Michell MG, et al. An African, multi-centre evaluation of patient care and clinical outcomes for patients with COVID-19 infection admitted to high-care or intensive care units. Lancet 2020 (epub 22 October 2020). https://doi.org/10.2139/ssrn.3707415

4. RT Staff. Early data on intubated COVID-19 patients reveals severe mortality. 9 April 2020. https://www: rtmagazine.com/disorders-diseases/critical-care/icu-ventilation/early-data-on-ventilated-covid-19tmagazine.com/disorders-diseases/cricul-care/icu-ve

5. Bisso IC, Huespe I, Lockhart C, et al. Clinical characteristics of critically ill patients with COVID-19. 5. Bisso IC, Huespe I, Lockhart C, et al. Clinical characteristics of critically ill patient
medRxiv 2020 (epub 11 December 2020). https://doi.org/10.1101/2020.12.09.20246413

6. Socolovithc RL, Fumis RRL, Tomazini BM, et al. Epidemiology, outcomes, and the use of intensive care unit Socolovithc RL, Fumis RRL, Tomazini BM, et al. Epidemiology, outcomes, and the use of intensive care unit
resources of critically ill patients diagnosed with COVID-19 in Sao Paulo, Brazil: A cohort study. PLoS ONE 2020;15(12):e0243269. https://doi.org/10.1371/journal.pone.0243269

7. Worldometer. COVID-19 coronavirus pandemic 2020. 2021. https://www.worldometers.info/coronavirus/ (accessed 5 April 2021).

8. World Health Organization. Laboratory testing for 2019 novel coronavirus (2019-nCoV) in suspected human cases. 19 March 2020. https://www.who.int/publications//ititem/10665-331501 (accessed 14 April 2021).

9. ARDS Definition Task Force. Acute respiratory distress syndrome: The Berlin definition. JAMA 2012;307(23):2526-2533. https://doi.org/10.1001/jama.2012.5669

10. Chew SY, Lee YS, Ghimiray D, Tan CK, Chua GSW. Characteristics and outcomes of COVID-19 patients with respiratory failure admitted to a 'pandemic ready' intensive care unit - lessons from Singapore. Ann Acad Med Singapore 2020;49:434-448. https://doi.org/10.47102/annals-acadmedsg.2020161

11. Wang Y, Lu X, Li Y, et al. Clinical course and outcomes of 344 intensive care patients with COVID-19. Am J Respir Crit Care Med 2020;201(11):1430-1434. https://doi.org/10.1164/rccm.202003-0736le 12. Laverdure F, Delaporte A, Bouteau A, Genty T, Decailliot F, Stéphan F. Impact of initial respiratory
compliance in ventilated patients with acute respiratory distress syndrome related to COVID-19. Crit Care compliance in ventilated patients with acute respiratory dist

13. Grasselli G, Zangrillo A, Zanella A, et al. Baseline characteristics and outcomes of 1591 patients infected with SARS-CoV-2 admitted to ICUs of the Lombardy Region, Italy. JAMA 2020;323(16):1574-1581. https:// doi.org/10.1001/jama.2020.5394

14. Cummings MJ, Baldwin MR, Abrams D, et al. Epidemiology, clinical course, and outcomes of critically ill adults with COVID-19 in New York City: A prospective cohort study. Lancet 2020;395(10239):1763-1770. https://doi.org/10.1016/s0140-6736(20)31189-2

15. Bhatraju PK, Ghassemieh BJ, Nichols M, et al. Covid-19 in critically ill patients in the Seattle region - case series. N Engl J Med 2020;382:2012-2022. https://doi.org/10.1056/nejmoa2004500

16. Larsson E, Brattström O, Agvald-Öhman C, et al. Characteristics and outcomes of patients with COVID-19 admitted to ICU in a tertiary hospital in Stockholm, Sweden. Acta Anaesth Scand 2021;65(1):76-81. https:// doi.org/10.1111/aas.13694

17. Xu J, Yang X, Yang L, et al. Clinical course and predictors of 60 -day mortality in 239 critically ill patients with COVID-19: A multicenter retrospective study from Wuhan, China. Crit Care 2020;24(1):394. https://doi.
. COVID-19: A multicenter retros
org/10.1186/s13054-020-03098-9

18. Calligaro GL, Lalla U, Audley G, et al. The utility of high-flow nasal oxygen for severe COVID-19 pneumonia Calligaro GL, Lalla U, Audley G, et al. The utility of high-flow nasal oxygen for severe COVID-19 pneumonia
in a resource-constrained setting: A multi-centre prospective observational study. EClinicalMedicine 2020;28:100570. https://doi.org/10.1016/j.eclinm.2020.100570

19. Michell W, Joubert I, Peters S, et al. The organisational response of a hospital critical care service to the COVID-19 pandemic: The Groote Schuur Hospital experience. South Afr J Crit Care 2021;37(2):63-69. https://doi.org/10.7196/SAJCC.2021.v37i2.503

20. Garcia PDW, Aguirre-Bermeo H, Buehler PK, et al. Implications of early respiratory support strategies on disease progression in critical COVID-19: A matched subanalysis of the prospective RISC-19-ICU cohort. Crit Care 2021;25:175. https://doi.org/10.1186/s13054-021-03580-y

21. Gopalan D, Joubert I, Paruk F, Levy B. Allocation of scarce critical care resources during the COVID-19 public health emergency in South Africa. Critical Care Society of Southern Africa, 2 April 2020. https:// criticalcare org za/wp-content/uploads/2020/04/Allocation-of-Scarce-Critical-Care-Resources-Duringthe-COVID-19-Public-Health-Emergency-in-South-Africa.pdf (accessed 25 March 2021).

22. Western Cape Department of Health, South Africa. Western Cape Provincial Critical Care Triage and 2. Western Cape Department of Health, South Africa. Western Cape Provincial Critical Care Triage and
Decision Tool. 18 May 2020. https://www.westerncape.gov.za/assets/departments/health/h83_2020 Decision Tool. 18 May 2020. https://www.westerncape.gov.za/assets/departm
covid-19 covid_critical_care triage_and_decision_tool.pdf (accessed 1 April 2021).

23. New York State Department of Health. New York State Department of Health and New York State Task New York State Department of Health. New York State Department of Health and New York State Task
Force on Life and the Law Update Ventilator Allocation Guidelines. 25 November 2015. https://www.health. ny.gov/press/releases/2015/2015-11-25_ventilator_allocation_guidelines.htm (accessed 1 April 2021).

24. News24. Covid-19 dashboard: Track the spread, recovery and mortality statistics. Data source from National Department of Health and NICD. https://covid-19dashboard.news24.com/ (accessed 24 August 2021).

25. Horby P, Lim WS, Emberson J, et al. Dexamethasone in hospitalised patients with Covid-19. N Engl J Med 2020;384:693-704. https://doi.org/10.1056/nejmoa2021436

26. Mkhize Z. New COVID-19 variant identified in SA. 18 December 2020. https://sacoronavirus. co.za/2020/12/18/new-covid-19-variant-identified-in-sa/ (accessed 13 April 2021),

Accepted 8 November 2021 